\title{
Australia's National Tobacco Campaign
}

\section{Hill, T Carroll}

S moking is the single greatest preventable cause of premature death and disease in Australia. ${ }^{1}$ In 1998 approximately 19000 deaths in Australia were attributable to the use of tobacco. ${ }^{2}$ Almost $10 \%$ of the total burden of disease in Australia in 1996 was estimated to be attributable to tobacco smoking. ${ }^{3}$ After consistent declines in the prevalence of smoking from around $60 \%$ of men and $30 \%$ of women in the early $1960 s,{ }^{4}$ this reduction appeared to stall in the early 1990 s at around $27 \%$ of men and $23 \%$ of women. ${ }^{5}$

Australia is a federal system in which responsibilities for funding and delivery of therapeutic and preventive health services is shared between national and State jurisdictions. Statewide tobacco control campaigns were initially developed in Australia by some State jurisdictions during the early 1980s. Since then, campaigns have been developed and implemented within Australian States and Territories as part of increasingly comprehensive tobacco control programmes. In addition to this, the Federal government and a range of non-government organisations have also undertaken tobacco control campaign activity.

Despite steady reductions in tobacco use in the 1980s and early 1990s, workers in the tobacco control field became concerned by the mid-1990s about an apparent stalling of the previously declining prevalence of smoking. The field was calling for new initiatives to restore tobacco to prominence on the public health agenda. Before her party lost office in 1995, the Federal Health Minister Dr Carmen Lawrence set aside funds for a research effort to reduce smoking in the community. In 1996, the new Federal Health Minister Dr Michael Wooldridge made a firm commitment to increase measures to reduce smoking prevalence in Australia. The Federal government recognised the potential gains that could be derived from pooling the extensive tobacco control knowledge and resources throughout Australia to develop a collaborative national anti tobacco campaign. The government committed Australian\$7 million over two financial years to a cessation focused National Tobacco Campaign (NTC) targeting smokers aged $18-40$ years.

Coordinated by the Australian Department of Health, with advice from an expert advisory committee, the NTC was launched in June 1997 and has continued since this time. As a mass media led campaign, the NTC is the most intense and longest running anti tobacco campaign ever seen in Australia. One of its more outstanding aspects concerns the value of cooperative partnerships with Federal and State/Territory jurisdictions and interested non-government organisations. State and Territory governments and quit campaigns have contributed resources and funding to a range of supporting initiatives, absorbing many of the costs associated with an increased demand on cessation services. Furthermore, many States have provided additional funding to enhance the reach and frequency of Federal government advertising activity.

\section{CAMPAIGN STRATEGY DEVELOPMENT}

To inform the development of the campaign strategy, a review was undertaken of existing data consisting of 40 years of psychological research and more than a decade of largely unpublished market research reports commissioned by various Australian tobacco control "Quit" campaigns. More than 100 reports were identified, providing an invaluable perspective in determining the approach to be taken. In a simplification of the stages of change model and a large body of other behavioural theory and research, ${ }^{6}$ the brief to the advertising agency proposed an individual model based on a "personal agenda" about smoking.

Briefly, the model assumed the following:

(1) the day to day actions of individuals are largely explained by the existence of an unwritten personal agenda with items on it implicitly ranked for importance/urgency and grouped along the following lines: "today"; "tomorrow"; "sometime soon"; "if I ever get the chance"; "when I eventually get around to it"

(2) for intentions to become actions they must at least make it to today's agenda

(3) behaviours (like quitting) that require action over many days and which are difficult, require resources and reinforcements external to the individual.

It is known that most smokers "intend" to quit ${ }^{8}$ but clearly for most smokers, for most of the time, quitting was not on today's agenda. Hence, the major communication objective in the brief to the agency was that the campaign should elevate quitting on smokers' personal agendas. The brief also listed seven key facilitators of behaviour change. It stated that to potentiate an existing intention, an individual should be stimulated toward some or all of the following. He or she should:

(a) gain fresh insights on the recommended behaviour

(b) reassess the importance of the behaviour

(c) reassess the urgency of carrying out the behaviour

(d) reassess the personal relevance of the behaviour

(e) have confidence in their own ability to carry out the behaviour (self efficacy)

(f) remember or be reminded to do it

(g) for long term change, gain more than is lost by carrying out the behaviour (response efficacy).

Further, taking account of results of the review of the qualitative research that was undertaken, the advertising brief indicated that the campaign should:

(a) show the damage of smoking in new insightful ways that are both enlightening ("now I see what the doctors are concerned about") and chilling ("I can not bear to think of that happening to $\mathrm{me}^{\prime \prime}$ )

(b) develop a conditioned association between the images of bodily harm and the act of smoking such that those images come to mind when smoking is contemplated or seen.

Given that people are more likely to act on the basis of what they experience than what they are told, the communication challenge for the campaign was to translate the scientific knowledge about smoking into "felt" experience, rather than induce merely a cognitive appreciation of risk. Acknowledging that people do not think probabilistically or behave "rationally" in relation to probabilities, " the core rationale behind the content of the campaign as it was executed was to describe the 
Table 1 Advertisements used in the Australian campaign from 1997

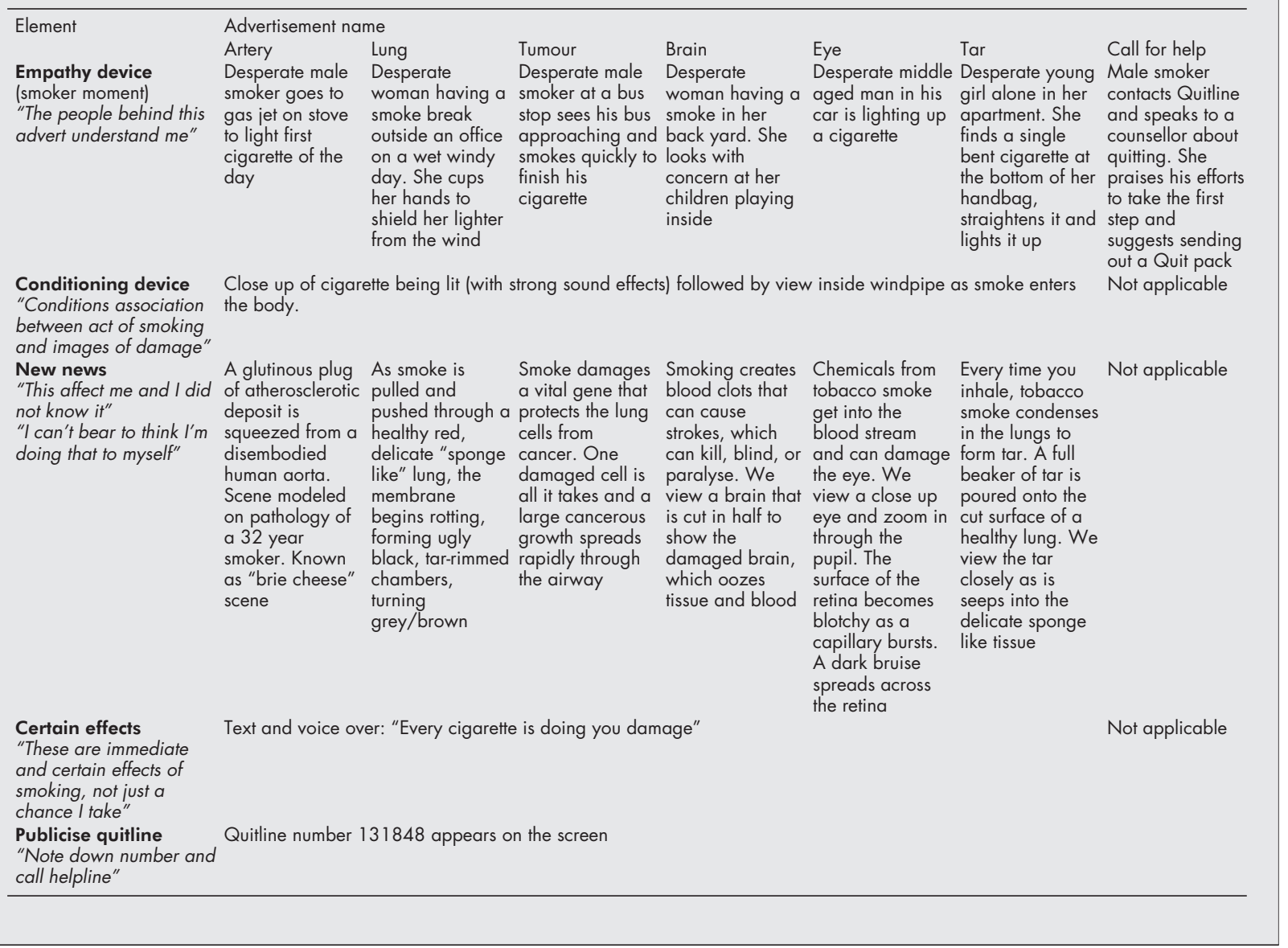

certain consequences of smoking, even if they are less dire than the uncertain ones, such as lung cancer and heart attacks.

\section{ADVERTISING MATERIALS}

Powerful "health effects" television advertisements were developed as the core communications materials for the campaign. These health effects advertisements have four distinct components, each designed to achieve a specific hypothesised outcome:

(1) an empathetic portrayal of a slightly awkward but typical smoking moment, to show that the intent of the advertisement is to understand and help smokers, not hector them

(2) a sequence of visuals to forge a strong associative link (through repeated screening of advertisements) between the acts of lighting/inhaling a cigarette and images of the harm when smoke enters the body

(3) "new news" about the damage smoking does, presented as graphic negative health effects

(4) a slogan "Every cigarette is doing you damage" to stress the ongoing effects of smoking and to counter the smokers' rationalisation that smoking is like a lottery (you are fine unless your number comes up).

The creative team from the advertising agency Brown, Mehuish, and Fishlock were brought into direct contact with medical specialists in the cardiovascular, neurology, and respiratory fields.

These meetings provided important insights for the creative development team in understanding the mechanisms and manifestations of tobacco related disease and in particular visualising ways to describe it in lay language. The medical consultants became an integral part of the process of developing and launching the advertisements, providing clinical research data to ensure the accuracy of the disease mechanisms depicted in the advertisements, offering relevant advice in filming the clinical aspects of advertisements, and acting as media spokespersons.

Informed by earlier research identifying smokers' needs, the health effects advertisements were designed to be visceral and confronting, and it was intended that the smoker's reaction would be "I can not bear to think I am doing that to myself". At the end of each advertisement the national Quitline number was displayed. Each smoker calling this number had access to trained smoking cessation counsellors, as discussed later.

Each advertisement brought smokers some "new news" about smoking, but more than this, the message was framed in such a way as to maximise the effect on behaviour. Firstly, the emphasis was on relatively certain rather than less probable effects. Thus, the campaign slogan was "Every cigarette is doing you damage" and the advertisements focused upon ongoing damage, that is, the things that happen as you smoke now, rather than long delayed clinical outcomes. An overview of how these devices were operationalised for each television advert is summarised in table 1 .

In June to October 1997, three television advertisements focusing on health effects were used ("artery", "lung, and "tumour"). In each of the advertisements, the viewer travels with the smoke as it is inhaled down the trachea and into the lungs, where it begins its deadly work. Artery, which features "gruel" (fatty deposits) being squeezed by a surgeon's gloved hand from a human aorta, was the first advertisement 
Table 2 Implementation of the National Tobacco Campaign advertisements and media expenditure

\begin{tabular}{llllll}
\hline TV adverts & $\begin{array}{l}\text { June } 97 \text { to } \\
\text { Oct } 97\end{array}$ & $\begin{array}{l}\text { Nov } 97 \text { to } \\
\text { Oct } 98\end{array}$ & $\begin{array}{l}\text { Nov } 98 \text { to } \\
\text { Oct } 99\end{array}$ & $\begin{array}{l}\text { Nov } 99 \text { to } \\
\text { Oct } 00\end{array}$ & $\begin{array}{l}\text { Nov } 00 \text { to } \\
\text { Oct } 01\end{array}$ \\
\hline $\begin{array}{l}\text { Artery } \\
\text { Lung }\end{array}$ & $\Rightarrow$ & & & & \\
$\begin{array}{l}\text { Tumour } \\
\text { Call for help }\end{array}$ & $\Rightarrow$ & & & & \\
$\begin{array}{l}\text { Brain } \\
\text { Eye }\end{array}$ & & $\Rightarrow$ & & $\Rightarrow$ & \\
Tar & & & & & \\
Total media spend (Australian\$000 000) & $\$ 4.5$ & $\$ 6$ & $\$ 5$ & $\$ 5.5$ & $\$ 6.7$ \\
Average monthly expenditure (AUD) & $\$ 908,000$ & $\$ 503,000$ & $\$ 413,000$ & $\$ 456,000$ & $\$ 559,000$ \\
\hline
\end{tabular}

developed. Realism and relevance to the 18-40 year old target group was enhanced by modelling the artery advertisement on the actual pathology described for a 32 year old smoker recently reported in the medical literature. The second, lung, depicted emphysematous damage, and the third, tumour, outlined the recent discovery of a mechanism by which smoking damages the p53 tumour suppressor gene in lung tissue. ${ }^{10}$

The image of the aorta depicted in the artery advertisement (see Tob Control 1998;7(1):6 for print advert ${ }^{7}$ ) was to become the primary image utilised in other visual components of the advertising strategy, such as 24 sheet outdoor advertising, bus and tram sides, the campaign website (www.quitnow.info.au), and z-card" fold out information sheets containing quitting tips. Print advertisements (also produced as A3 posters) were developed utilising the images from artery, lung, and tumour. These were distributed to general practitioners (GPs) and pharmacists and extensively through State and Territory Quit campaign networks.

In addition to the television advertisements, nine radio advertisements were developed for airing in the first six months of the campaign. These four health effects radio advertisements, artery, lung, tumour, and see the damage, reinforced the information depicted in the television advertisements. The remaining five radio advertisements; "cravings", "coffee break", "money", "recovery rate", and "call quit first", provided supportive messages about the quitting process, such as dealing with cravings and avoiding triggers, and outlined the benefits of quitting, such as financial savings and reversal of disease processes.

In November 1997 to October 1998 an advertisement about stroke ("brain") and an advertisement modelling the behaviour of calling the Quitline ("call for help") were introduced to the mix of campaign communication materials. From the point of view of the creative execution, depiction of a stroke had all the ingredients of the artery advertisement; a potentially powerful "visceral" image, an autopsy specimen, and the credible image of a surgeon's gloved hands. It used the same creative approach as the initial three advertisements and depicted graphic images of smoking related stroke. Brain was based on the actual pathology documented in a case study of a 38 year old woman. Her age was highlighted in the voiceover to emphasise the early onset of disease processes and dispel the myth that you can smoke for many years before the damage occurs.

The call for help advertisement was developed in the light of formative research indicating some misunderstanding about the role of the Quitline and the need to produce an advertisement for this support service. Call for help was designed to position the service as accessible, friendly, and professional; to increase belief in the efficacy and acceptability of seeking support; and to provide encouragement to call the line. A behavioural modelling approach was used, depicting a smoker initiating a call to the Quitline.
In 1999 it was agreed that in order to maintain campaign momentum, the existing campaign strategic direction should be maintained, with a view to introducing new campaign materials in time for World No Tobacco Day (WNTD; 31 May) 2000. The task ahead was to extend the existing campaign and its relevance to target youth, while continuing to provide "new news" to smokers about the health effects of smoking. A number of new "smoker moments" were developed featuring younger smokers, aged 17-24 years. Recent research demonstrating a link between smoking and eye damage (macular degeneration), presented an opportunity to offer new information and fresh insights on the damage that smoking can do to the body, as well as generating the powerful imagery that had become a key ingredient of the campaign strategy to date.

Following concept testing research, two new television advertisements were produced; "eye" (macular degeneration) and "tar" (tar build up in the lungs). Tar graphically suggests the damage that smoking does to the body by pouring a beaker of tar ("the amount of tar that a pack a day smoker inhales") over a lung. The formative research showed that this image generated a sense of relevance and urgency with smokers. This effect is heightened among the 16-24 year old target group through modelling a younger smoker moment in the advertisement.

Eye describes the process of the eye damage (macular degeneration) that is caused by chemicals from tobacco smoke entering the bloodstream. This health effect combines powerful imagery of the damage occurring in a smoker's eye with a strong new news element.

\section{CAMPAIGN IMPLEMENTATION}

Within the target group of 18-40 year old smokers, a lower socioeconomic bias was introduced into the choice of media placement to reflect the social class gradient of smoking in Australia. Television was selected as the primary medium. The level of exposure achieved in the first six months of the campaign by placement of the advertising on television, radio, print, outdoor, and supermarket trolleys served to achieve the objective of prompting and reminding the smoker to quit.

Phase one of the campaign was launched in June 1997 (table 2) at a press conference with major national media organisations attending, and this marked the commencement of the advertising schedule for artery and lung. Four weeks of relatively high media advertising activity followed. The tumour advertisement was also launched at a large press conference. The airing of the advertisements during the news and current affairs coverage of the launch events considerably extended the reach and impact of the paid advertising. After the initial weeks of high level advertising, a one week break preceded the launch of tumour, which was placed for three weeks at medium weight. A break of three weeks in August 
was followed by a week on/week off schedule of medium to low level advertising activity for three months, ending in November 1997. After the first six months, over $80 \%$ of $18-40$ year old smokers reported having seen the television advertising. ${ }^{11}$

In phase two of the national media campaign there were three flights of paid media advertising. The first commenced in late December 1997 to early January 1998 in an intense "New Year" campaign. The second flight occurred in April to June 1998 with the launch of brain and call for help and ran through WNTD to finish in June. The final flight of advertising commenced at the beginning of October and finished in early December 1998.

The strategy for media placement followed three general principles. The first was to create a cyclical flighting schedule that would incorporate "natural" quit dates such as WNTD and New Year. The second was to continue to use television as the primary communication medium with target audience rating point (TARP) levels of between 100 and 200 per week to maintain Quitline call levels with maximum efficiency*. A third principle involved avoiding the December preChristmas period, during which there is substantial retail advertising clutter and evidence for reduced interest in quitting. ${ }^{12}$ In addition to television advertising, radio and print advertisements were used within the New Year and WNTD promotions. ${ }^{1}$

During the April to May 1998 launch period of the brain and call for help advertisements, a "double spotting" regimen was applied to maximise the impact of the push-pull effect; the health effects advertisement placed first followed by call for help, at the beginning and end of the commercial break. A 15 second version of call for help was produced later in 1998 to maximise the flexibility and efficiency of media buying.

The periodic media flighting schedule that had been adopted for the campaign in 1998 was continued through 1999 and 2000, with a focus on television media advertising at particular key times of the year. The double spotting strategy was also carried through 1999-2000.

National media activity in 1999 commenced with New Year campaign activity to capitalise on this "natural" time of year for smokers to consider implementing a resolution to quit smoking. This phase was followed up by television and radio advertising leading up to and following WNTD 1999. This period has become a significant focal point for the NTC each year and builds upon the extensive promotional and publicity activities undertaken by State and Territory Quit organisations on this international day.

During the springtime (Southern hemisphere) months of September and October, a time when many Australians take on the challenge of improving their fitness and getting "into shape", the campaign undertook a six week period of television advertising. This advertising activity also included strategies particularly targeted toward smokers of non-English speaking backgrounds, including television advertising on the multicultural broadcaster, SBS, and community based strategies with State Quit organisations.

The challenge of "quitting for the new millennium" provided a valuable opportunity for the campaign over the New Year 2000 period and a strong schedule of television advertising was staged from late December 1999 until early January 2000. Tactical radio advertising encouraging smokers

*TARPs are the conventional units for buying media time on television. TARPs represent the potential weight of advertising exposure to a designated target audience in terms of the proportion of the target audience exposed to a television advertisement, and the number of times they are exposed. to quit at this auspicious time supported this television advertising. The WNTD 2000 phase (4b) of campaign activity saw the introduction of the two new campaign advertisements tar and eye. The initial introduction of the tar advertisement on WNTD was followed by the launch of eye in mid-June, and the campaign phase continued with the pairing of each advertisement with the Quitline call for help advertisement until midJuly.

Two flights of national campaign activity were undertaken during 2001, around New Year's celebrations and WNTD. These flights employed a mix of health effects and call for help television advertisements, at times using the double spotting strategy outlined above. At the same time, State and Territory Quit campaigns undertook a range of tobacco control campaign activities. Further information about TARP levels (from 1997) is contained in the paper by Wakefield et al in this supplement. ${ }^{11}$

\section{THE TELEPHONE QUITLINE}

To maximise the chance of the intended behavioural response, each campaign advertisement carried the number of the Quitline telephone service. Smokers who were stimulated to quit, but wanted assistance, could contact the Quitline.

In recognition that a successful national advertising campaign would create demand for cessation support and information, building the capacity of the Quitline service throughout Australia was an integral part of the campaign strategy. This involved funding to support upgrading of equipment, use of a telecommunications service in large States (so that a large number of calls could be answered simultaneously), training of staff, and national monitoring of call numbers and response rates. Simultaneously, a quality improvement programme resulted in a greater consistency of service and measures to ensure service compatibility with research evidence. Smokers who took that first step towards quittingcalling the Quitline- were often successful in the longer term. ${ }^{13}$

\section{PARTNERSHIPS AND STRATEGIC ALLIANCES}

The generic branding "NTC - a federal, state, and territory health initiative" encouraged broad ownership of campaign materials and facilitated the involvement of a range of partner organisations. A partnership strategy was developed in recognition that strategic alliances would reinforce the credibility of the campaign, extend the reach of its messages, and provide wider access to the target group. Representatives from many peak medical and health organisations have acted as media spokespersons in their various areas of specialty. Informing GPs about campaign development and enlisting their support in promoting of cessation activity has also been a major focus of partnership activity. A campaign postcard thanked doctors for their support, and encouraged them to promote cessation within their practice setting. A tear-off postage paid reply card invited them to order 20 free copies of the Quit book to give to patients. Additional mail outs to GPs have included fact sheets and clinical information regarding campaign advertisements. A timely boost for the campaign was delivered by the pharmaceutical companies manufacturing nicotine replacement therapy. Those with the major market share became very active in the marketplace during 1997 as a result of regulatory change to permit direct consumer advertising of transdermal nicotine replacement. Although no formal partnership existed between the NTC and the Australian pharmaceutical industry, since this time campaign advertising has often coincided with considerable consumer marketing activity for nicotine replacement therapy. 


\section{STRATEGY FOR PEOPLE FROM A NON-ENGLISH SPEAKING BACKGROUND}

As part of the NTC, a communication strategy specifically targeting people from non-English speaking backgrounds in eight languages other than English was launched in February 1998. This strategy was developed in recognition of higher smoking prevalence among particular ethnic groups, as well as their varying levels of English language proficiency, length of time since migration, and their use of mainstream and ethnic communication media. The target audience for the strategy was male and female smokers and recent quitters aged 18-40. Demographic and smoking prevalence data among people from culturally and linguistically diverse backgrounds informed the language groups to be targeted. These were Italian, Greek, Arabic, Vietnamese, Chinese (Mandarin and Cantonese), Spanish, Korean, and Turkish. Based on language spoken at home these groups number approximately 1.4 million people. ${ }^{14}$ The formative stage of the strategy involved obtaining information on the social and cultural aspects of smoking in each community. Qualitative research conducted with selected language groups suggested that the main campaign was widely recognised because of the bold imagery and strong visual narrative of the television advertisements. ${ }^{15}$ The components of the non-English speaking backgrounds strategy were ethnic radio and press advertising; publicity; initiatives with workplaces; GPs; and bilingual health and medical community members. With some refinement, the mainstream campaign materials provided a strong platform on which to build communications with non-English speaking audiences, with many of these smokers reporting discussing smoking in the home and being influenced by family members to quit during the campaign period. $^{15}$

\section{CAMPAIGN FUNDING}

Over its first six months of operation, around Australian $\$ 8$ million of Federal, State, and Territory funding was devoted toward the campaign, including around Australian $\$ 4.5$ million being spent on the advertising media buy, with the bulk of this funding coming from the Federal government. From 1998 the campaign has continued at a "maintenance" level of funding, with the Federal government providing approximately Australian $\$ 2.2$ million per annum. By 2001 funding support provided by State and Territory Quit campaigns and other partner organisations had grown to represent nearly $70 \%$ of the annual NTC expenditure.

\section{EVALUATION OF THE NTC}

The NTC is probably the most comprehensively evaluated national health promotion campaign mounted in Australia to date. The Australian NTC achieved high rates of recall and recognition, was appraised favourably by smokers, contributed to new learning about smoking and health, and increased agreement with the campaign related attitudes. ${ }^{16}$ These findings applied equally to smokers of lower and higher occupational status and educational status. ${ }^{16-17}$ Furthermore, although the campaign was not targeted at teenagers, the vast majority of adolescents were aware of the campaign and thought the campaign was relevant to them. ${ }^{18}$ The volume of calls to the Quitline by Australian smokers was strongly related to TARPs and increased further when an advert promoting the Quitline was broadcast. ${ }^{19} 20$

\section{CONCLUSION}

The Australian NTC has been the longest running coordinated mass media led campaign to reduce smoking in
Australia. It has potentiated increased levels of collaboration between States in tobacco control and has been a factor in several states increasing their financial commitment to tobacco control. As shown by the papers in this supplement, the campaign evaluations suggest it has been effective in a number of ways.

Although overall investment in tobacco control generally and in mass media led campaigns in particular has increased since the mid-1990s, the success of Australia's campaign has been achieved with financial resources that fall far short of the levels of investment in regions where sustained and substantial reductions in tobacco use have been reported. ${ }^{21-22}$ To maintain and extend these achievements, it will be important to ensure that policy makers and the public do not perceive that successes to date signify that the tobacco problem has been brought under control. An ongoing and adequately funded comprehensive commitment will be essential.

\section{Authors' affiliations}

D Hill, The Cancer Council Victoria, Victoria, Australia

T Carroll, The Australian Department of Health and Ageing, Sydney,

Australia

For correspondence: D Hill, The Cancer Council Victoria, 1 Rathdowne St Carlton Victoria 3053, Australia; david.hill@cancervic.org.au

\section{REFERENCES}

1 Commonwealth Department of Health and Aged Care. National tobacco strategy 1999 to 2002-03. A framework for action. Canberra: Commonwealth of Australia, 1999.

2 Australian Institute of Health and Welfare. Statistics on drug use in Australia 2002. AlHW cat.no. PHE 43 (Drug Statistics Series no. 12). Canberra: Australian Institute of Health and Welfare, 2003

3 Mathers C, Vos T, Stevenson C. The burden of disease and injury in Australia. Canberra: Australian Institute of Health and Welfare, 1999.

4 Woodward SD. Trends in cigarette consumption in Australia. Australian and New Zealand Journal of Medicine 1984;14:405-7.

5 Hill DJ, White VM, Scollo MM. Smoking behaviors of Australian adults in 1995: trends and concerns. Med J Aust 1998;168:209-13.

6 Prochaska JO, DiClemente CC, Norcross JC. In search of how people change: applications to the addictive behaviours. Am Psychol 1992;47: 1102-14.

7 Hill D, Chapman S, Donovan R. The return of scare tactics. Tob Control 1998;7:5-8.

8 Mullins R, Morand M, Borland R. Key findings of the 1994 and 1995 household surveys. In: Mullins R, ed. Quit Evaluation Studies No.8 1994-1995. Australia: Victorian Smoking and Health Program, 1996.

9 Fischhoff B, Slovic P, Lichtenstein S. Lay foibles and expert fables in judgements about risk. The American Statistician 1992;36(3):240-55.

10 Denissenko $M$, Pao A, Tang $M$, et al. Preferential formation of benzo[a]pyrene adducts at lung cancer mutational hotspots in p53. Science 1996;274:430-2.

11 Wakefield M, Freeman J, Donovan R. Recall and response of smokers and recent quitters to the Australian National Tobacco Campaign. Tob Control 2003;12(Suppl II):ii 15-22.

12 Donovan R, Freeman J, Borland R, et al. Tracking the National Tobacco Campaign. In: Hassard K, ed. Australia's National Tobacco Campaign, evaluation report volume one. Canberra: Commonwealth Department of Health and Aged Care, 1999.

13 Miller C, Wakefield M, Roberts L. Uptake and effectiveness of the Australian telephone Quitline service in the context of a mass media campaign. Tob Control 2003;12(Suppl II):ii53-8.

14 Australian Bureau of Statistics 1996. Census of Population and Housing. Basic Community Profile. Catalogue No 2020.0. Canberra; Commonweath of Australia, 1997.

15 Carroll T, Katz C, Carvill K. The National Tobacco Campaign: targeting people from non-English speaking backgrounds. In: Hassard K, ed. Australia's National Tobacco Campaign, evaluation report volume one. Canberra: Commonwealth Department of Health and Aged Care, 1999. 
16 Wakefield $M$, Freeman J, Boulter J. Changes associated with the National Tobacco Campaign: pre and post campaign surveys compared. In: Hassard K, ed. Australia's National Tobacco Campaign: evaluation report volume one. Canberra: Commonwealth Department of Health and Aged Care, 1999.

17 Tan M, Wakefield M, Freeman J. Changes associated with the National Tobacco Campaign: results of the second follow-up survey. In: Hassard K, ed. Australia's National Tobacco Campaign: evaluation report volume two. Canberra: Commonwealth Department of Health and Aged Care, 2000

18 White V, Tan N, Wakefield M, et al. Do adult focused anti-smoking campaigns have an impact on adolescents? The case of the Australian National Tobacco Campaign. Tob Control 2003;12(Suppl II):ii23-9.

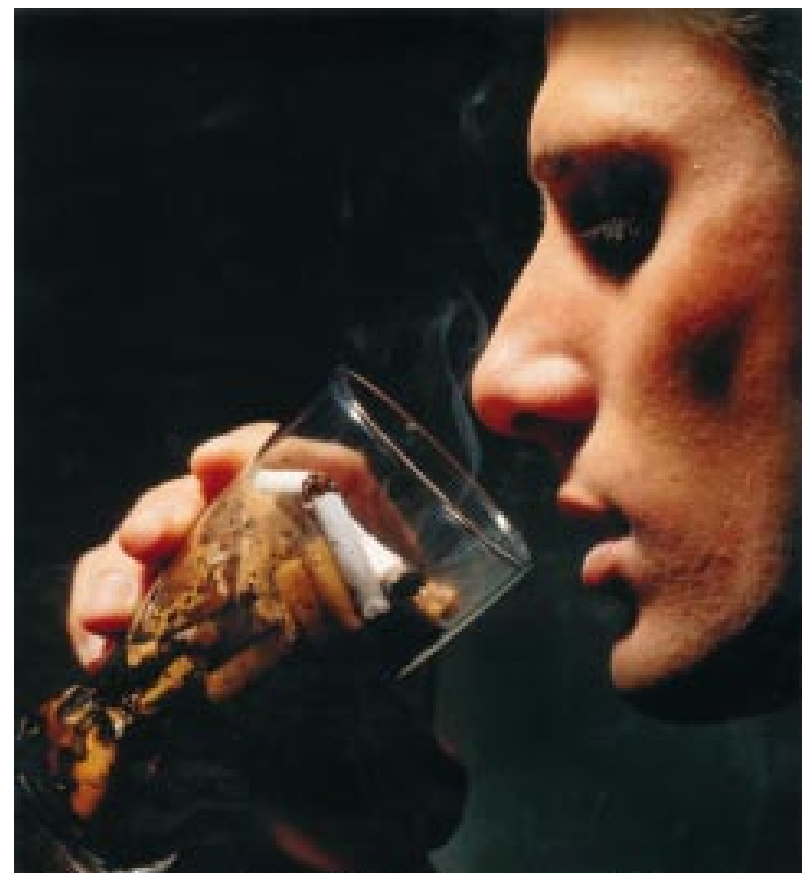

\section{SMOKING IN BARS CAN KILL}

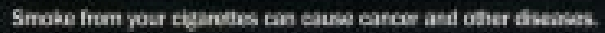

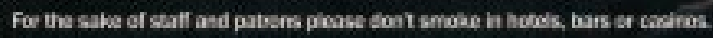
Think about the pacple at the bar ans help protsct thet hears.

\section{ACOSI के}

This arresting image was used to promote the need for smoke free bars and clubs in Western Australia to protect the health of workers. Reproduced with kind permission of The Australian Council on Smoking and Health (ACOSH).
19 Donovan RJ, Boulter J, Borland R, et al. Continuous tracking of the Australian National Tobacco Campaign: advertising effects on recall, recognition, cognitions, and behaviour. Tob Control 2003;12(Suppl II): ii30-9.

20 Carroll T, Rock B. Generating Quitline calls in Australia's National Tobacco Campaign: effects of television advertisement execution and programme placement. Tob Control 2003;12(Suppl II):ii40-4.

21 Biener L, Harris JE, Hamilton W. Impact of the Massachusetts tobacco control programme: population based trend analysis. BM 2000:321 (7257):351-4.

22 Pierce J, Gilpin E, Emery S, et al. Has the California tobacco control program reduced smoking? JAMA 1998;280(10):893-9

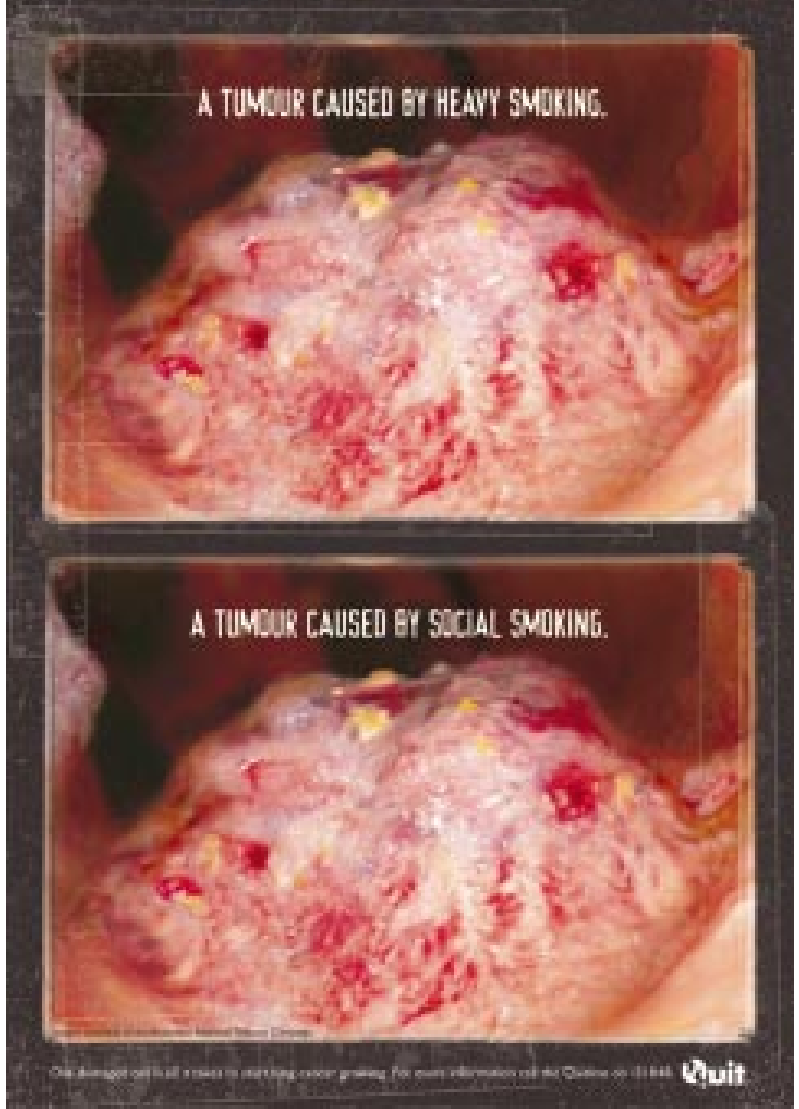

This image from the National Tobacco Campaign's "Tumour" television advert was recycled to contribute to a campaign in Western Australia which aimed to illustrate the point that cancer can occur among social smokers and heavy smokers. Contributed by Gino Marinucci, Quit Western Australia. 